\title{
PATTERN OF EPISTAXIS AND ITS TREATMENT MODALITIES: THE HYDERABAD EXPERIENCE
}

\author{
Rais Uddin Siddiqui, Rafi Ahmed Ghauri and M. Rafique K.K.
}

\begin{abstract}
OBJECTIVE: To evaluate the pattern of epistaxis and its treatment modalities in our set up. DESIGN: A descriptive case series.

SETTING: Ear Nose Throat (ENT) department of Liaquat University Hospital Hyderabad, Sindh during years 2001 to 2003.

METHODS: This study comprised of 350 cases of nose bleeding managed at ENT department. Patients belonged to all ages from infancy to old, with different presentation and causes. Case records of all these cases were analyzed retrospectively.

RESULTS: Majority of patients (63\%) was male and $35.4 \%$ patients were between $16-30$ years age. Bleeding due to existing nasal pathology was seen in 140 cases. Nasal trauma as a cause of epistaxis was present in 125 cases (35.7\%), blood dyscrasia in 25 cases and 20 patients had metabolic disorders. Among 280 cases $(80 \%)$ anterior bleeding was present. One hundred cases required immediate nasal packing to control the bleeding. Surgical procedures included nasal ploypectomy and septoplasty in $\mathbf{1 5}$ cases each while rhinolith and foreign bodies were removed in 15 and 25 cases respectively. Fifty cases were treated with immediate cauterization of the bleeding point. In 15 cases with malignancy of nose and sinuses, initially radiotherapy was considered to decrease the vascularity of tumors. Only 20 cases did not require any treatment except cold sponging and direct digital pressure.

CONCLUSION: Epistaxis is not an ignorable emergency. It is the manifestation of multiple local and other systemic disorders. To reduce the morbidity and mortality, appropriate management is the key factor. The emergency department of all hospitals shall have proper equipment and facilities to examine and manage the cases. Cauterization of bleeding point by hot wire or chemical agent to stop the bleeding is still valuable in recurrent epistaxis.
\end{abstract}

KEY WORDS: Epistaxis. Treatment. Emergency.

\section{INTRODUCTION}

Human beings are experiencing the problem of nose bleeding i.e. epistaxis from the earliest times in the history. Hippocrates used to stop bleeding by applying external pressure and writing magic words on the forehead of patient. ${ }^{1}$ In a general population, $10-12 \%$ persons suffer from this problem. ${ }^{2}$ According to O'Donnell, et al, its incidence is 108 per 100,000 population per year, ${ }^{3}$ and from $26.4-26.8 \%$ in 100,000 population per year require admission in accident and emergency departments in UK. ${ }^{4}$ Any nasal insult that disrupt the normal mucosa can result in epistaxis. Nose bleeding is more common during the winter season and in hot, dry climates when the nasal cavity becomes dry with stasis of nasal secretions; nasal mucosa becomes infected, more vascular, prone to ulcerate easily thus resulting in epistaxis. In children, apart from the bleeding disorders, a foreign body in nose is a common cause leading to friability of nasal mucosa ensuing bleeding. In most of such cases for the control of epis- taxis, major surgical treatment is not required. Removal of foreign body and a properly placed nasal packing is sufficient to control it. In the recurrent cases, a search for the cause and bleeding point is important. Use of hot wire and chemical agent for cauterization initially help to control and stop the bleeding ${ }^{5}$ along with other treatment modalities. However, in the presence of major trauma and existing nasal pathological conditions, surgical manuals become mandatory to deal the problem. This paper presents the pattern of epistaxis and outcome of its treatment modalities in our set up.

\section{PATIENTS AND METHODS}

This study of 350 cases of epistaxis was conducted at Department of Ear Nose and Throat Liaquat University Hospital, Hyderabad, Sindh during 2001-2003. Medical records of patients admitted from out patients department, referred from the causality department, and surgical and medical wards were analyzed. Complete 
history regarding onset of epistaxis, age, sex, profession, previous episodes, self-medication, personal and family history and the measures to control it were obtained. In children, the hematological assessment included complete blood picture, $\mathrm{Hb} \%$, TLC, DLC, platelets count, prothrombin time, activated partial prothrombin time, and bleeding and clotting times. Plain radiology for the nose, para-nasal sinuses and base of skull in cases of trauma and C.T scan in selected cases of sinu-nasal mass to judge the extent and involvement of other areas were also done. Treatment options included cauterization of bleeding points, anterior and posterior nasal packing and surgery.

\section{RESULTS}

Among 350 cases of epistaxis, 220(63\%) were male and $130(37 \%)$ female patients. Out of these, $35(10 \%)$ patients belonged to age group of 01-05 years, 100 cases (28.5\%) to 06-10 years and 124 patients (35.4\%) were between 16-30 years. Meanwhile, 91 cases $(26 \%)$ were above the age of 30 years. Nasal trauma as a cause of epistaxis was seen in 125 cases (35.7\%) and spontaneous bleeding with no immediate cause noted in 40 cases (5.7\%). The bleeding due to existing nasal pathology was seen in 140 cases, blood dyscrasia in 25 cases and 20 patients with metabolic disorders such as hypertension, liver diseases (Table I). Among 280 cases (80\%) anterior bleeding was present while posterior bleeding was seen in 35 cases
(10\%). Remaining 35 cases had bleeding from both anterior and posterior aspects. One hundred cases required immediate nasal packing (anterior nasal packing in 80 and posterior nasal packing in 20 cases) to control the bleeding. In presence of traumatic bleeding, the correction of fractured bones leading to nasal deformity was done along nasal packing in 70 cases, while 75 cases, after the evaluation of the nasal pathologies required surgery. Surgical procedures included nasal ploypectomy in 15, septoplasty in 15, rhinolith removed in 15 and foreign bodies removal in 25 cases. In 2 cases, the tumor was removed via trans- palatal, lateral rhinotomy while partial maxillectomy was done in 3 cases. Fifty cases were treated with immediate cauterization of the bleeding point (in 10 cases chemical cautery, in 20 cases hot wire cautery and diathermy excision for minor bleeding polypus/ septal haemingioma in 20 cases). In 15 cases with malignancy of nose and sinuses, initially radiotherapy was considered to decrease the vascularity of tumors. Bleeding due to deficient coagulation factors was controlled in 20 cases by replacement and blood transfusion. There were only 20 cases that did not require any treatment except cold sponging and direct digital pressure. Patients with hypertension and liver diseases and blood disorders were managed in collaboration with medical specialist accordingly (Table II).

TABLE I:

CAUSATIVE FACTORS OF EPISTAXIS IN PATIENTS OF DIFFERENT AGE GROUPS

\begin{tabular}{|c|c|c|c|c|c|}
\hline \multirow{2}{*}{ Causative factor } & \multicolumn{4}{|c|}{ Age group } & \multirow[b]{2}{*}{$\begin{array}{c}\text { Total number } \\
\text { of patients }\end{array}$} \\
\hline & 01-05 years & 06-15 years & $16-30$ years & $\begin{array}{l}31 \text { years } \\
\text { onwards }\end{array}$ & \\
\hline Idiopathic & 5 & 20 & 10 & 5 & 40 \\
\hline Trauma & 8 & 40 & 50 & 27 & 125 \\
\hline Blood disorder & 5 & 5 & 5 & 10 & 25 \\
\hline Infection & 5 & 5 & 10 & - & 20 \\
\hline Septal spur & - & 10 & 10 & 5 & 25 \\
\hline Nasal polyps & - & 3 & 5 & 7 & 15 \\
\hline Bleeding polyps & - & 3 & 12 & 5 & 20 \\
\hline Rhinolith & - & 4 & 8 & 3 & 15 \\
\hline Foreign bodies & 12 & 10 & 3 & - & 25 \\
\hline Angio-fibroma & - & - & 5 & - & 5 \\
\hline Malignancy & - & - & 3 & 12 & 15 \\
\hline Metabolic disorder & - & - & 3 & 17 & 20 \\
\hline
\end{tabular}




\section{TABLE II: \\ TREATMENT MODALITIES FOR PATIENTS WITH EPISTAXIS}

\begin{tabular}{|l|c|c|}
\hline \multicolumn{1}{|c|}{ Treatment } & $\begin{array}{c}\text { Number } \\
\text { of cases }\end{array}$ & $\begin{array}{c}\text { Per- } \\
\text { centage }\end{array}$ \\
\hline Digital pressure/cold sponging & 20 & 5.7 \\
\hline Nasal packing(anterior/posterior) & 100 & 28.5 \\
\hline Fracture reduction/rhinoplasty & 70 & 20 \\
\hline Sino-nasal surgery & 75 & 21.5 \\
\hline Chemical / electric cautery & 50 & 14.3 \\
\hline Radiotherapy & 15 & 4.3 \\
\hline Supportive therapy & 20 & 5.7 \\
\hline
\end{tabular}

\section{DISCUSSION}

Epistaxis is regarded as the most common emergency in the practice as Rhinologist. In all patients, an initial resuscitation must be vital procedure to stop the bleeding and to reduce the morbidity and mortality in the emergency department. ${ }^{6}$ The importance to enquire about the frequency and duration of epistaxis along with current medication and assessment of coagulation disorder ${ }^{7}$ is the vital element in the history. In the management of epistaxis, an initial assessment of bleeding site is important along with replacement of blood loss and treatment of the underlying cause helps to reduce both morbidity and mortality. ${ }^{1}$ Two areas often involve in nose bleeding; Keisselbachs plexus (giving rise to anterior bleeding), and Woodruff's plexus (giving rise to posterior bleeding). Keisselbach plexus is on the anterior septum formed by anastomoses between sphenopalatine, greater palatine, superior labial, and ethmoid arteries. Woodruffs plexus is located over the posterior middle turbinate and is made up of anastomoses between branches of the internal maxillary artery, namely the posterior nasal, sphenopalatine, and ascending pharyngeal. The maxillary sinus ostium is the dividing line between anterior and posterior epistaxis. Anterior bleeding is easier to access and is less dangerous. Posterior epistaxis is more difficult to treat as visualization is more difficult and blood is often swallowed making it difficult to assess the amount of blood loss. Various treatment modalities are adapted to control the nose bleeding but there is no uniformly accepted criterion for the management of epistaxis. Simple digital pressure, cold sponging and ice packing is still regarded as the initial first aid method ${ }^{8}$ although generally accepted but not much fruitful. In this study, this method was successful in only 20 cases out of 350 to control bleeding. Nasal packing is regarded as a favorable and widespread method to control epistaxis, when the externally applied pressure fails. In this study, 70 cases under went anterior nasal packing and posterior nasal packing were done in 30 cases immediately. Uniform pressure on bleeding sites by ribbon packs soaked with ointment and Bismuth lodine Paraffin Paste provides good result in anterior bleeding. We used Foleys catheter in posterior bleeding, although this method is generally successful but there is always an unpleasant feeling and discomfort by the patient along with the risk of mucosal trauma, sinusitis, otitis media, hypoxia, hypercapnoea, sepsis, and toxic shock syndrome. ${ }^{9}$ In the presence of existing nasal pathologies, with recurrent episodes of persistent and intractable bleeding when the traditional method fails to control, surgery becomes the choice to remove the cause. $^{10,11}$ In this series, septal surgery was done in 15 cases. Infected nasal polyps were removed in 15 cases, rhinolith in 15 , and small foreign bodies from nasal cavity were removed in 25 cases. In 2 cases, via trans- palatal and lateral rhinotomy approach angiofibroma was removed and in 3 cases partial maxillectomy was done for malignant growth. Recently, angiography and embolisation of feeding vessel is done in centers where this facility is available. This helps to minimize the bleeding during and after surgery. Moreover, ligation of main feeding vessels is also considered in uncontrolled bleeding. In this series, no case required this option.

In cases where the bleeding point is identified and easily visible, to reduce the discomfort of nasal packing cauterization has been practiced for centuries. ${ }^{12}$ Variety of methods of cautery are in use including Silver Nitrate, Tricholoroacetic acid and hot wire cautery. ${ }^{13}$ We used hot wire cautery in 40 cases and Silver Nitrate cautery in 10 cases. In all these cases the bleeding point was easily visible on the nasal septum. Silver Nitrate cautery is suitable for children with out any anaesthesia. In cases of small bleeding polypus and haemingioma, hot wire cautery and diathermy excision successfully removed and controlled the intractable epistaxis. The care should be taken to avoid unnecessary damage to normal nasal mucosa. However, in cases of posterior bleeding points the transnasal rigid nasal endoscopic cauterization is the treatment of choice to avoid unnecessary mucosal burn. ${ }^{14}$ Cautery in the case of congenital vascular anomaly like hereditary haemorrhagic telengectasia is avoided as it induces more aggregasive bleeding and other methods to control nasal bleeding like embolisation of vascular tree, laser photocoagulation, endoscopic and open arterial ligation, septo-dermoplasty, young's procedure, and the auto grafting by using buccal mucosa and application of fibrin glue are in use at different places. ${ }^{15}$ In this series, for cases of malignancy with 
recurrent epistaxis radiotherapy was considered to reduce the size and vascularity of the tumor. In epistaxis with existing hypertension and other metabolic disorders, combined anterior and posterior nasal packing was done along with the physician advice to complement the treatment. In this series, there were 12 cases with known hypertension and 8 cases with liver diseases which were successfully managed with nasal packing.

In conclusion, epistaxis is not an ignorable emergency. It is the manifestation of multiple local and other systemic disorders of the body. To reduce the morbidity and mortality, appropriate management is the key factor and emergency departments of all hospitals shall have proper equipment and facilities to examine and manage such cases. In children, infections, foreign bodies and coagulation disorders must be excluded as causative factors. However, young patients usually suffer this problem due to accidents and trauma along with nasal pathologies while old aged patients need attention due to malignancy and metabolic disorders. Among different modalities of treatment, properly placed nasal packing and early cauterization of the visible bleeding point are still valuable methods to control epistaxis in emergency.

\section{REFERENCES}

1. Courdes S. Epistaxis. UTMB Department of Otolaryngology, Grand Rround Archives, 1996.

2. Shaheen $\mathrm{OH}$. Epistaxis. In: Mackay IS, Bull Tr (eds.). Scott Brown's Otolaryngology. $5^{\text {th }}$ Edition. London. Butterworths, 1987: Pp. 272-82.

3. O'Donnell M, Robertson G, McGray GW. A new bipolar diathermy probe for outpatient management of adult acute epistaxis. Clin Otolaryngology. 1999; 24:537-41.

4. Small M, Murray JAM, Moran AGD. A study of patients with epistaxis requiring admission to hos- pital. Hospital Health Bull. 1982; 40:20-9.

5. Srinivasan V, Sherman IW, O'Sullivan G. Surgical management of intractable epistaxis: audit of results. J Laryngol Otol. 2000; 14:697-700.

6. Wild DC, Spraggs PD. Treatment of epistaxis in Accident and Emergency departments in UK. J Laryngol Otol. 2002; 116:597-600.

7. Jones GL, Browning S, Phillipps J. The value of coagulation profiles in epistaxis management. Int J Clinic Pract. 2003; 57: 577-8.

8. Tevmoortash A, Sesterhenn A, Kress R, Sapundzhiev N, Werner JA. Efficacy of ice packs in the management of epistaxis. Clin Otolaryngol Allied Sci. 2003;28:545-7.

9. Jensen PF, Kristensen S, Juul A, Johannessen NW. Episodic nocturnal hypoxia and nasal packs. Clin Otolaryngol Allied Sci. 1991; 16:433-5.

10. Barlow DW, Deleyiannis WB, Pinczower Ef. Effectiveness of surgical management of epistaxis at a tertiary care centre. Laryngoscope. 1997;107:21-24.

11. Monux A, Tomas M, Kaiser C, Gavilan J. Conservative management of epistaxis. J Laryngol Otol. 1990; 104:868-70.

12. Pothula V, Alderson D. Nothing new under the sun: the management of epistaxis. J Laryngol Otol.1998; 112:331-4.

13. Quine SM, Gray RF, Rudd M, von Blumenthal $H$. Microscope and hot-wire cautery management of 100 consecutive patients with acute epistaxis: a superior method to traditional packing. J Laryngol Otol. 1994; 108: 845-8.

14. Alderson D. Simple device for chemical cauterization of posterior bleeding point in nose. J Laryngol Otol. 2000; 114:616-17.

15. Farnan TB, Gallagher G, Scally CM. A novel treatment for patient with hereditary haemorrhagic telangiectasia. J Laryngol Otol. 2002; 116:849-50.

AUTHOR AFFILIATION:

Prof. Rais Uddin Siddiqui (Corresponding Author)

Department of Ear Nose Throat

Liaquat University of Medical and Health Sciences

(LUMHS) Jamshoro, Sindh - Pakistan.

E-mail: rais_ent@yahoo.com

Prof. Rafi Ahmed Ghauri

Department of Medicine

LUMHS Jamshoro, Sindh - Pakistan.

Dr. M. Rafique K.K.

Senior Lecturer, Department of Ear Nose Throat

LUMHS Jamshoro, Sindh - Pakistan. 